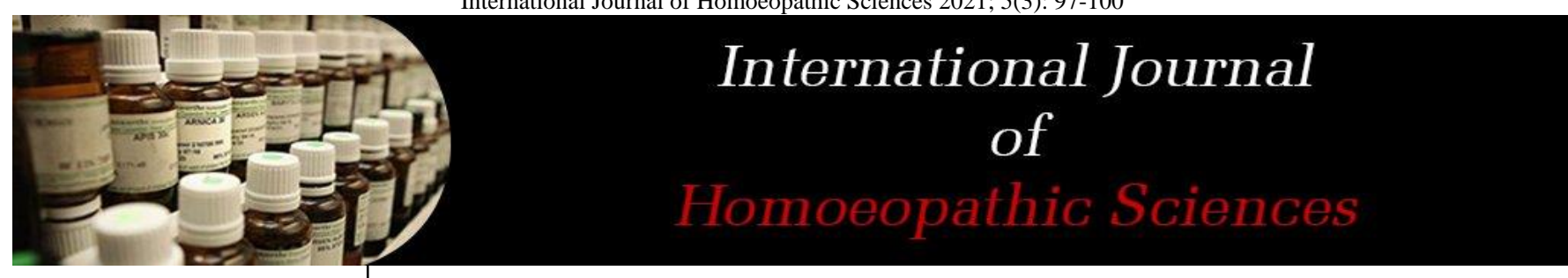

E-ISSN: $2616-4493$ P-ISSN: 2616-4485 www.homoeopathicjournal.com IJHS 2021; 5(3): 97-100

Received: 28-05-2021

Accepted: 30-06-2021

Dr. Navita Bagdi BHMS, MD (H), Research Associate (H), CCRH Headquarters, Ministry of Ayush, Government of India, New Delhi, India
Corresponding Author: Dr. Navita Bagdi BHMS, MD (H), Research Associate (H), CCRH Headquarters, Ministry of Ayush, Government of India, New Delhi, India

\section{Arsenic and its effect on immunity: A narrative review}

\section{Dr. Navita Bagdi}

DOI: $\underline{\text { https://doi.org/10.33545/26164485.2021.v5.i3b.413 }}$

\begin{abstract}
Introduction: Human immune system has evolved through eons of struggle between the host and pathogens. Although Arsenic can act as immunostimulant by causing an elevation of inflammatory responses in our body, the immunosuppressive effects of Arsenic include modulation of the numbers, survival and functions of immune and hematopoietic cells and impaired humoral and cell-mediated immunity. Immunomodulation is a kind of regulatory modification in the immune system to bring the desired response. Homoeopathy embraces a holistic approach in curing diverse diseases and it is used globally as an alternative medicine and seeks to cure in harmony with natural laws of healing. The present review focusses on the collection of results of studies carried out on effect of arsenic on immunity.
\end{abstract}

Methodology: In this review literature available from various published studies and databases like PubMed, Springer, Elsevier and AYUSH research portal and references from the relevant articles published literature were searched in English language up to December 2020.

Results: 25 studies were included in this review of which 10 in vivo, 9 in vitro, 2 Ex vivo and 4 review articles. Most of the studies substantiate the definitive role of Arsenic on immunomodulation.

Conclusion: In future extensive studies are required to further explore the immunomodulatory effects of homoeopathic medicines Arsenicum album and studies based on human-derived immune cells need more attention.

Keywords: immunomodulation, arsenic, In vivo studies, In vitro studies, arsenic trioxide

\section{Introduction}

Arsenic (As) a major toxic human carcinogen and environmental contaminant ${ }^{[1]}$ is present everywhere in nature and human being exposed to arsenic via ground water, atmospheric air, and food sources ${ }^{[2]}$. More than 200 million people worldwide are exposed to arsenic contaminated ground water at a level more than the permissible limit $(<10 \mathrm{ppb})^{[3]}$. Arsenic exposure may not only affect and disable organs of the body, but it can also interfere with the proper functioning of the immune system ${ }^{[4]}$ and result in growth retardation, gross pathology including skin and eye lesions, ulcerations, cataract development etc ${ }^{[5]}$. In human and various animal models, arsenic has been found to alter immune response either by severe suppression or activation which may eventually lead to increased susceptibility to pathogens or hypersensitivity disorder, respectively. Arsenic exposure altered the relative distribution of different $\mathrm{T}$ cell subpopulation $\left(\mathrm{CD}^{+}\right.$count, $\mathrm{CD} 8^{+}$count, $\mathrm{Th} 1, \mathrm{Th} 2$, $\mathrm{Th} 17, \mathrm{~T}$ reg) in exposed population as well as in-vitro arsenic exposed human ${ }^{[6]}$.

\section{Methodology}

\subsection{Search Strategy}

The literature for the present review was identified using electronic databases including PubMed, Springer, Elsevier and AYUSH research portal and references from the relevant articles published literature. Keywords used for this literature review include 'Arsenic', 'Immunomodulation' and their MeSH variations in PubMed. The search strategy was designed to include all the studies containing the descriptors that were published until December 2020.

\subsection{Study Selection}

2.2.1 Inclusion criteria

Publications of the English language only were included. 


\subsubsection{Exclusion criteria}

All the clinical studies were excluded. Review articles, Letters to the editor, conference proceedings and comments were also excluded. Unpublished data such as dissertations, data not published in peer-reviewed journals, and websites were not included.

\section{Discussion}

\subsection{Use of Arsenic in Traditional Medicine}

Arsenic compound has been used as Fowler's solution was used in the treatment of various diseases such as malaria, syphilis, asthma, chorea, eczema, psoriasis and as cancer chemotherapeutic ${ }^{[7]}$. In 1880, the pharmacology texts described the use of arsenical pastes for the treatment of skin and breast cancer. In 1878, it was found that Fowler's solution could be effective in lowering the white blood cell count in leukaemia patients. ${ }^{8}$ Result of various studies shows that arsenic trioxide is effective in the treatment of acute promyelocytic leukaemia (APL). In 2001, the efficacy of arsenic trioxide was demonstrated in the treatment of end-stage high-risk multiple myeloma and now in the present scenario arsenic trioxide is approved to treat relapsed or refractory APL and research is continuing to determine its efficacy in other haematological cancers. ${ }^{9}$ In Traditional Chinese Medicine arsenic trioxide or arsenous acid paste is often used to treat tooth marrow disease as a devitalizing agent. It has also been used against some other diseases such as psoriasis, syphilis, and rheumatosis ${ }^{[10]}$.

\subsection{Use of Arsenic in Modern Medicine}

In Western medicine, arsenic was used more recently (until the advent of penicillin) in the treatment of syphilis. Due to the known carcinogenic effect its only therapeutic use today is in the treatment of trypanosomiasis involving the central nervous system ${ }^{[11]}$. Arsenic trioxide is an anticancer drug, sold under the brand name Trisenox and used to treat refractory or relapsed acute promyelocytic leukemia. It is believed that it induces apoptosis (programmed cell death) of promyelocytic leukemia cells. It was included in the World Health Organization's 21st List of Essential Medicines published in 2019 as one of the safest and most effective medicines needed in a health system ${ }^{[12]}$.

\subsection{Use of Arsenic as a Pigment and Other Products}

Arsenic's use as a pigment (e.g., Paris Green or copper acetoarsenite) in the 1800s was suspected as a major source of unintentional arsenic poisonings. Although the arsenicbased pigment was used in many consumer products (e.g., toys, candles, and fabric) it uses in wallpaper was particularly linked to widespread sickness and death during this period Arsenic trioxide is effective in inducing and maintaining remission in patients with APML with minimal side effects ${ }^{[13]}$. Data from various studies shows that arsenic trioxide may be a useful addition to the therapeutic regimens that have been so successful in treating newly diagnosed APL and investigations are ongoing to incorporate this agent into the first-line APL treatment paradigm. Preliminary data from clinical studies indicate that arsenic trioxide has clinical activity as a single agent in MDS and $\mathrm{MM}$, and combination therapies are being investigated ${ }^{[14]}$.

\subsection{Use of Arsenic in Ayurveda}

Ayurveda is the traditional Indian medicinal system with a holistic approach to health and personalized medicine. It is known to be a complete medical system that comprised physical, psychological, philosophical, ethical, and spiritual health ${ }^{[15]}$. In India, Ayurvedic arsenic-containing compound is described, which is used to control blood counts of patients with haematological malignancies. The efficacy and side effects of this compound are evaluated in the light of the fact that arsenic was recognised to be of use in the control of blood counts from patients with chronic myeloid leukaemia ${ }^{[16]}$.

\subsection{Use of Arsenic in Unani}

The Unani medicine is considered as one of the oldest and time-tested systems of medicine practiced since more than 2500 years ${ }^{[17]}$. In Unani system of medicine arsenic is use as Samm al-Fär to treat nervous disorders, sexual disorders, skin disorders, anaemia, fevers, respiratory disorders, and joints pain ${ }^{[18]}$.

\subsection{A few examples to substantiate immunological evidence is stated here.}

It was found that arsenic reduced paracetamol-induced analgesia possibly by interfering with pronociceptive 5HT2A and antinociceptive CB1 receptors ${ }^{[19]}$.

The effect of As on T cell population is mainly attributed to altered expression of key immune regulator molecules impaired T cell functions, cytokines production, induction of apoptosis, and oxidative stress induction in T cells ${ }^{[20]}$.

In an in vitro study, it was found that three kinds of arsenic compounds, at high doses suppressed the plaque forming cell response to sheep erythrocytes and the proliferative response to mitogens, whereas at low doses they enhanced both responses [21]. In another study arsenic exposure makes $L$. rohita immunocompromised and could increase its susceptibility to pathogen attacks. It was observed in the study that arsenic has a generalized immune-suppressive effect leading to down regulation of both Th1 and Th2 cytokines; besides, it led to up regulation of the HSP genes indicating arsenic-induced cellular stress ${ }^{[22]}$.

A study was conducted by Duan X et al. on female mice showed that arsenic significantly decreased the spleen and thymus weights and flow cytometry revealed that arsenic decreased the relative frequency of $\mathrm{CD} 4+\mathrm{T}$ cell subpopulation and the ratios of CD4/CD8 in spleen [23]. whereas in another study it was found that effect of Arsenicum album $30 \mathrm{C}$ is effective in upregulating $\mathrm{T}$ lymphocytes such as CD4, CD8 and CD4:CD8 ratio ${ }^{[24]}$ In a study conducted by Gupta V.K et al it was seen in that homoeopathic medicines produced modulation of immune function at multiple levels such as modulation of expression of genes, stimulation of macrophage and polymorph nuclear cells, changes in expression of surface receptors and induction of cytokines ${ }^{[25]}$.

\section{Conclusion}

Homoeopathy is a natural system of healing the ailing humans from diseases and an unquestioned method of antidoting/detoxifying the chemotherapeutic effects that render the human body susceptible to novel diseases. Homoeopathy treats the individual as a whole while providing individualised treatment, homeopathy is particularly effective at helping patients strengthen their natural immunity. The Homoeopathic medicines produced modulation of immune function at multiple levels. This evidence suggests that homoeopathic treatment has the 
potential for individual-specific immunomodulation. So far, the numbers of homoeopathic medicines studied for their immunomodulatory function are few as compared to the vast repertoire of homoeopathic medicines available to the profession. In future, more pre-clinical studies are needed to explore the action of homoeopathic medicines at cellular level and their possible role in individual-specific immunomodulation.

\section{References}

1. Banerjee S, Mitra T, Purohit GK, Mohanty S, Mohanty BP. Immunomodulatory effect of arsenic on cytokine and HSP gene expression in Labeo rohita fingerlings. Fish Shellfish Immunol 2015;44(1):43-9. doi: 10.1016/j.fsi.2015.01.029. Epub 2015 Jan 31. PMID: 25652292.

2. Abdul KS, Jayasinghe SS, Chandana EP, Jayasumana C, De Silva PM. Arsenic and human health effects: A review. Environ Toxicol Pharmacol 2015;40(3):82846.doi: 10.1016/j.etap.2015.09.016. Epub 2015 Sep 30. PMID: 26476885.

3. Naujokas MF et al. The broad scope of health effects from chronic arsenic exposure: update on a worldwide public health problem. Environmental Health Perspectives (Online) 2013;121:295

4. Duker AA, Carranza EJ, Hale M. Arsenic geochemistry and health. Environ Int 2005;31(5):631-41. doi: 10.1016/j.envint.2004.10.020. Epub 2004 Dec 8. PMID:

5. Banerjee S, Mitra T, Purohit GK, Mohanty S, Mohanty BP. Immunomodulatory effect of arsenic on cytokine and HSP gene expression in Labeo rohita fingerlings. Fish \&amp; Shellfish Immunology 2015;44(1):43-49. DOI: 10.1016/j.fsi.2015.01.029.

6. PBMCs Gera R, Singh V, Mitra S et al. Arsenic exposure impels CD4 commitment in thymus and suppress $\mathrm{T}$ cell cytokine secretion by increasing regulatory T cells. Sci Rep 2017;7:7140

7. Rohe GH. Arsenic. In Reference-Book of Practical Therapeutics, (F. P. Foster,Ed.) 1896;1:142-146. D. Appleton and Company, New York. Available at: http://www.archive.org/details/cu31924104225978. Accessed July 27, 2011. [Google Scholar]

8. Antman KH. Introduction: the history of arsenic trioxide in cancer therapy. Oncologist 2001;6(2):12. [PubMed] [Google Scholar]

9. Röllig C, Illmer T. The efficacy of arsenic trioxide for the treatment of relapsed and refractory multiple myeloma: a systematic review. Cancer Treat Rev. 2009;35(5):425-30. doi: 10.1016/j.ctrv.2009.04.007. Epub 2009 May 22. PMID: 19464807.

10. Chen ZY, Liu TP, Yang Y. (eds): Manual of Clinical Drugs. Shanghai, China, Shanghai Science and Technology 1995, 830.

11. Correia MA, Becker CE. Chelators and heavy metal intoxication, in Katzung BG (eds): Basic and Clinical Pharmacology, fourth ed. London, UK, Prentice-Hall, 1989, 7478 Finch RG, Snyder IS: Antiprotozoal drugs, in Craig CR, Stitzel RE (eds): Modern Pharmacology. Boston, MA, Little, Brown 1982, 698

12. Anonymous. Arsenic Trioxide Monograph for Professionals 2019. Accessed from https://www.drugs.com/monograph/arsenictrioxide.html on July 07, 2020 (9) (PDF) Historical
Ethnopharmacological Review Of A Unani Mineral Drug Samm Al-Far (Arsenic Trioxide). Available from: https://www.researchgate.net/publication/343987476_H istorical_Ethnopharmacological_Review_Of_A_Unani _Mineral_Drug_Samm_Al-Far_Arsenic_Trioxide [accessed Jun 07 2021].

13. Mathews V, Balasubramanian P, Shaji RV, George B, Chandy M, Srivastava A. Arsenic trioxide in the treatment of newly diagnosed acute promyelocytic leukemia: a single center experience. Am J Hematol. 2002;70(4):292-9. doi:10.1002/ajh.10138. PMID: 12210810 .

14. Amadori S, Fenaux P, Ludwig H, O\&\#39; dwyer M, Sanz M. Use of arsenic trioxide in haematological malignancies: insight into the clinical development of a novel agent Curr Med Res Opin 2005;21(3):403-11. doi: 10.1185/030079904X20349.PMID: 15811209 .

15. Semwal DK, Mishra SP, Chauhan A, Semwal RB. Adverse health effects of tobacco and role of Ayurveda in their reduction. J Med Sci. 2015;15:139-46. [Google Scholar]

16. Jennie Treleaven, Simon Meller, Peter Farmer, Derek Birchall, John Goldman. amp; Gordon Piller Arsenic and Ayurveda, Leukemia \&amp; Lymphoma, 1993; 10(4, 5):343-345, DOI: $10.3109 / 10428199309148558$

17. Lone AH, Ahmad T, Anwar M, Sofi G, Imam H, Habib S. Perception of health promotion in Unani herbal medicine. J Herb Medic 2012;2(1):1-5.

18. Michael F, Hughes, Barbara D, Beck, Yu Chen, Ari S et al. Arsenic Exposure and Toxicology: A Historical Perspective, Toxicol Sci 2011;123(2):305-332

19. Vijayakaran K, Kesavan M, Kannan K, Sankar P, Tandan SK, Sarkar SN. Arsenic decreases antinociceptive activity of paracetamol: possible involvement of serotonergic and endocannabinoid receptors. Environ Toxicol Pharmacol 2014;38(2):397405. doi: 10.1016/j.etap.2014.07.001. Epub 2014 Jul 10. PMID: 25128769.

20. Haque R, Chaudhary A, Sadaf N. Immunomodulatory Role of Arsenic in Regulatory T Cells. Endocr Metab Immune Disord Drug Targets 2017;17(3):176-181. doi:10.2174/1871530317666170818114454. PMID: 28820073.

21. Yoshida T, Shimamura T, Shigeta S. Immunological effects of arsenic compounds on mouse spleen cells in vitro. Tokai J Exp Clin Med 1986;11(5):353-9. PMID:672564.

22. Banerjee S, Mitra T, Purohit GK, Mohanty S, Mohanty BP. Immunomodulatory effect of arsenic on cytokine and HSP gene expression in Labeo rohita fingerlings. Fish Shellfish Immunol 2015;44(1):43-9. doi: 10.1016/j.fsi.2015.01.029. Epub 2015 Jan 31. PMID: 25652292.

23. Duan $\mathrm{X}$, Gao $\mathrm{S}$, Li $\mathrm{J}$ et al Acute arsenic exposure induces inflammatory responses and $\mathrm{CD} 4+\mathrm{T}$ cell subpopulations differentiation in spleen and thymus with the involvement of MAPK, NF-kB, and Nrf2, Molecular Immunology, 2017;81:160-172, ISSN 01615890, https://doi.org/10.1016/j.molimm.2016.12.005.

24. Marangattil Varghese, Thomas, Ghosh O Sivaraman Nirmal, Damodaran, Bijukumar KC, Muraleedharan SG Biju. Efficacy of arsenicum alb 30c for upregulating immunological markers among residents of covid-19 
related hot spot areas in Pathanamthitta, Kerala 2020.

10.13140/RG.2.2.26387.71200.

25. Gupta VK, Mathur M. Immunomodulatory effects of homoeopathic medicines: A review of pre-clinical studies. Indian J Res Homoeopathy 2018;12:90-4. 